\title{
PET Imaging of Phosphodiesterase-4 Identifies Affected Dysplastic Bone in McCune-Albright Syndrome, a Genetic Mosaic Disorder
}

\author{
Lora D. Weidner*1, Yuichi Wakabayashi*1, Louise A. Stolz ${ }^{1}$, Michael T. Collins ${ }^{2}$, Lori Guthrie ${ }^{2}$, Milalynn Victorino ${ }^{1}$, \\ Joyce Chung ${ }^{3}$, William Miller ${ }^{1}$, Sami S. Zoghbi ${ }^{1}$, Victor W. Pike ${ }^{1}$, Masahiro Fujita ${ }^{1}$, Robert B. Innis ${ }^{\dagger 1}$, and \\ Alison M. Boyce ${ }^{\dagger 2}$ \\ ${ }^{I}$ Molecular Imaging Branch, National Institute of Mental Health, National Institutes of Health, Bethesda, Maryland; ${ }^{2}$ Skeletal \\ Disorders and Mineral Homeostasis Section, National Institute of Dental and Craniofacial Research, National Institutes of Health, \\ Bethesda, Maryland; and ${ }^{3}$ Office of the Clinical Director, National Institute of Mental Health, National Institutes of Health, Bethesda, \\ Maryland
}

McCune-Albright syndrome (MAS) is a mosaic disorder arising from gain-of-function mutations in the GNAS gene, which encodes the $3^{\prime}, 5^{\prime}$-cyclic adenosine monophosphate (cAMP) pathway-associated $\mathrm{G}$-protein, $\mathrm{G}_{\mathrm{s}} \mathrm{a}$. Clinical manifestations of MAS in a given individual, including fibrous dysplasia, are determined by the timing and location of the GNAS mutation during embryogenesis, the tissues involved, and the role of $\mathrm{G}_{\mathrm{s}} \mathrm{a}$ in the affected tissues. The $\mathrm{G}_{\mathrm{s}} \mathrm{a}$ mutation results in dysregulation of the CAMP signaling cascade, leading to upregulation of phosphodiesterase type 4 (PDE4), which catalyzes the hydrolysis of cAMP. Increased cAMP levels have been found in vitro in both animal models of fibrous dysplasia and in cultured cells from individuals with MAS but not in humans with fibrous dysplasia. PET imaging of PDE4 with ${ }^{11} \mathrm{C}-(R)$-rolipram has been used successfully to study the in vivo activity of the cAMP cascade. To date, it remains unknown whether fibrous dysplasia and other symptoms of MAS, including neuropsychiatric impairments, are associated with increased PDE4 activity in humans. Methods: ${ }^{11} \mathrm{C}-(R)$-rolipram whole-body and brain PET scans were performed on 6 individuals with MAS ( 3 for brain scans and 6 for whole-body scans) and 9 healthy controls (7 for brain scans and 6 for whole-body scans). Results: ${ }^{11} \mathrm{C}-(R)$-rolipram binding correlated with known locations of fibrous dysplasia in the periphery of individuals with MAS; no uptake was observed in the bones of healthy controls. In peripheral organs and the brain, no difference in ${ }^{11} \mathrm{C}-(R)$-rolipram uptake was noted between participants with MAS and healthy controls. Conclusion: This study is the first to find evidence for increased cAMP activity in areas of fibrous dysplasia in vivo. No differences in brain uptake between MAS participants and controls were detected-a finding that could be due to several reasons, including the limited anatomic resolution of PET. Nevertheless, the results confirm the usefulness of PET scans with ${ }^{11} \mathrm{C}-(R)$-rolipram to indirectly measure increased cAMP pathway activation in human disease.

Received Jan. 10, 2020; revision accepted Feb. 26, 2020.

For correspondence or reprints contact: Yuichi Wakabayashi, Molecular Imaging Branch, National Institute of Mental Health, National Institutes of Health, 10 Center Dr., Room B1D43, Bethesda, MD 20892.

E-mail: yuichi.wakabayashi@nih.gov

${ }^{*}$ Contributed equally to this work.

tContributed equally to this work.

Published online Apr. 13, 2020.

COPYRIGHT (C 2020 by the Society of Nuclear Medicine and Molecular Imaging.
Key Words: phosphodiesterase-4; McCune-Albright syndrome; CAMP; PET; ${ }^{11} \mathrm{C}-(R)$-rolipram

J Nucl Med 2020; 61:1672-1677

DOI: 10.2967/jnumed.120.241976

$\mathbf{M}$ cCune-Albright syndrome (MAS) is a rare genetic disorder arising from gain-of-function mutations in the GNAS gene (1). These mutations occur during the early embryogenesis of somatic cells and involve tissues derived from all 3 germ layers, which leads to a mosaic pattern of distribution. The GNAS mutation dysregulates the $3^{\prime}, 5^{\prime}$-cyclic adenosine monophosphate (cAMP) pathway-associated G-protein, $\mathrm{G}_{\mathrm{s}} \alpha$, which leads to increased cAMP signaling. Increased cAMP, in turn, leads to the clinical manifestations of MAS, which include a variable combination of fibrous dysplasia of bone (including craniofacial dysplasia), caféau-lait skin pigmentation, and hyperfunctioning endocrinopathies such as precocious puberty. The specific features of any given individual are determined by the timing and location of the GNAS mutation during embryogenesis, the tissues involved, and the role of $\mathrm{G}_{\mathrm{s}} \alpha$ in the affected tissues (2).

Because cAMP is part of a signal transduction cascade, increased cAMP levels lead to downstream effects, and affected cells respond by increasing the enzyme that regulates cAMP activity $(3,4)$. This regulation occurs through a negative feedback loop: increased cAMP stimulates protein kinase A (PKA), which in turn phosphorylates and activates phosphodiesterase enzymes (5). PDEs then metabolize cAMP to its inactive form, thereby terminating the signal. Phosphodiesterase type 4 (PDE4) is the major subtype of phosphodiesterase that metabolizes cAMP in brain and in some peripheral organs $(6,7)$. Previous in vitro studies found increased cAMP activity in mouse models of fibrous dysplasia as well as in primary cultures of bone cells from individuals with MAS (8-10); however, to date, this relationship has not been demonstrated in humans in vivo.

In addition to fibrous dysplasia and endocrinopathies, neuropsychiatric impairments such as intellectual disability, anxiety, and attentional deficits are also found in some individuals with MAS (11). Increased cAMP signaling could potentially be responsible for these 
findings, given the important role of cAMP signaling in the brain and the possibility that it could harbor GNAS mutations. Mouse models of analogous GNAS mutations in various brain regions demonstrated a potential link between activation of this pathway and various neuropsychiatric phenotypes (12-15). Nevertheless, the impact of the $\mathrm{G}_{\mathrm{s}} \alpha$ mutation on brain cAMP activity in individuals with MAS also remains unknown.

Notably, the PET tracer ${ }^{11} \mathrm{C}-(R)$-rolipram can be used to measure cAMP activity in humans. Rolipram is a reversible PDE4 inhibitor, and rolipram binding to PDE4 has been shown to increase with phosphorylation, meaning that ${ }^{11} \mathrm{C}-(R)$-rolipram provides a measure of activity as well as density $(16,17)$. In this context, ${ }^{11} \mathrm{C}$ $(R)$-rolipram binding indirectly reflects cAMP activity; that is, increased cAMP signaling increases ${ }^{11} \mathrm{C}-(R)$-rolipram binding.

This study investigated whether ${ }^{11} \mathrm{C}-(R)$-rolipram binding is increased in dysplastic bone, brain, or peripheral organs. To achieve this investigation, brain and whole-body PET scans with ${ }^{11} \mathrm{C}-(R)$-rolipram were performed on both healthy controls and participants with MAS.

\section{MATERIALS AND METHODS}

Radioligand Preparation

${ }^{11} \mathrm{C}$ - $(R)$-rolipram was labeled by ${ }^{11} \mathrm{C}$-methylation of $(R)$-desmethylrolipram as previously described (18). The radioligand exhibited a high radiochemical purity $(>99 \%)$ and had a molar activity of $87.45 \pm 47.22$ $\mathrm{GBq} / \mu \mathrm{mol}$ (mean $\pm \mathrm{SD}$ ) at the time of injection (22 batches).

\section{Participants}

This study (NCT02743377) was approved by the Institutional Review Board of the National Institute of Mental Health and Radiation Safety Committee of the National Institutes of Health. All participants provided written informed consent.

Six individuals with MAS and 9 healthy controls between the ages of 18 and $55 \mathrm{y}$ participated in the study (Table 1 shows their demographic characteristics). Of the 6 individuals with MAS, 2 had a clear neuropsychiatric phenotype (Table 2). Healthy controls were groupmatched for age and sex and had no history of any major psychiatric or neurologic disorder, as well as no current substance use disorder. All participants underwent a medical history, physical examination, analysis of blood chemistries, electrocardiograph, and pregnancy test for women of child-bearing age.

${ }^{11} \mathrm{C}-(R)$-rolipram whole-body and brain PET scans were performed on 6 individuals with MAS (6 had whole-body scans and 3 had brain scans) and 9 healthy controls (6 had whole-body scans and 7 had brain scans). All participants had a brain MRI scan and at least 1 PET scan (brain with arterial blood sampling or whole-body without arterial

TABLE 1

Participant Demographics

\begin{tabular}{cccc}
\hline Demographic & $\begin{array}{c}\text { Healthy control } \\
(n=9,13 \\
\text { scans })\end{array}$ & $\begin{array}{c}\text { MAS } \\
(n=6,9 \\
\text { scans })\end{array}$ & $P$ \\
\hline Age & $28 \pm 3.4$ & $39 \pm 2$ & 0.025 \\
\hline Proportion female & $78 \%$ & $83 \%$ & \\
\hline $\begin{array}{c}\text { Injected activity } \\
(\mathrm{MBq})\end{array}$ & $708 \pm 61$ & $725 \pm 84$ & 0.61 \\
$\begin{array}{c}\text { Molar activity } \\
(\mathrm{kBq} / \mathrm{nmol})\end{array}$ & $60 \pm 24$ & $81 \pm 41$ & 0.15 \\
$\begin{array}{c}\text { Mass dose } \\
(\mathrm{nmol} / \mathrm{kg})\end{array}$ & $0.19 \pm 0.1$ & $0.19 \pm 0.1$ & 0.99 \\
\hline
\end{tabular}


sampling) with ${ }^{11} \mathrm{C}-(R)$-rolipram. The scans were completed within 6 mo of the initial evaluation for this study. Four of the individuals with MAS had a previous ${ }^{18} \mathrm{~F}-\mathrm{NaF}$ bone scan that was used to identify areas of active fibrous dysplasia.

\section{Data Acquisition}

Whole-Body and Brain Imaging. Whole-body and brain scans with ${ }^{11} \mathrm{C}-(R)$-rolipram were performed as previously described $(19,20)$. Before injection, CT scans were obtained and used for attenuation correction. For both whole-body and brain scans, ${ }^{11} \mathrm{C}-(R)$-rolipram was injected intravenously over $1 \mathrm{~min}$, after which images were acquired for 120 and 90 min, respectively, with a Siemens Biograph mCT. For the brain scans ( 3 for individuals with MAS, 7 for healthy volunteers), arterial blood was sampled throughout the entire scan, with larger samples $(2-6 \mathrm{~mL})$ taken at specific time points for metabolite analysis and to measure plasma free fraction $\left(f_{\mathrm{P}}\right)$. A high-resolution 3-tesla MRI scan was obtained for all participants.

Calculation of ${ }^{11} C-(R)$-Rolipram Binding in Whole Body. The outcome measure used to calculate ${ }^{11} \mathrm{C}-(R)$-rolipram binding in peripheral organs and bone was SUV, which is the concentration of radioactivity normalized to injected activity and body mass. The following organs were analyzed: the liver, gallbladder, bladder, lungs, spine, spleen, kidneys, stomach, and heart, as well as dysplastic bone (including the skull). For dysplastic bone, participant-specific ${ }^{18} \mathrm{~F}-\mathrm{NaF}$ PET/CT scans were reviewed for areas of active fibrous dysplasia, identified by its typical ground-glass appearance and radiotracer uptake (Supplemental Fig. 1). Corresponding bone regions were also drawn on scans from healthy controls.

Calculation of ${ }^{11} C$ - $(R)$-Rolipram Binding in Brain. The outcome measure used to calculate ${ }^{11} \mathrm{C}-(R)$-rolipram uptake in the brain was total distribution volume $\left(V_{\mathrm{T}}\right)$. $V_{\mathrm{T}}$ was measured in 12 predefined regions: frontal cortex, temporal cortex, parietal cortex, occipital cortex, hippocampus, thalamus, striatum, cingulate, amygdala, globus pallidus, insula, and cerebellum. Regions were generated from the participant-specific MRI scan, which was then coregistered to the PET scan. Two of the MAS participants had fibrous dysplasia on 1 side of the skull; to determine whether this affected ${ }^{11} \mathrm{C}-(R)$-rolipram uptake, right-left differences in each region were also investigated. Partial-volume correction was also performed to determine whether brain deformations present in 2 of the MAS participants affected $V_{\mathrm{T}}$.

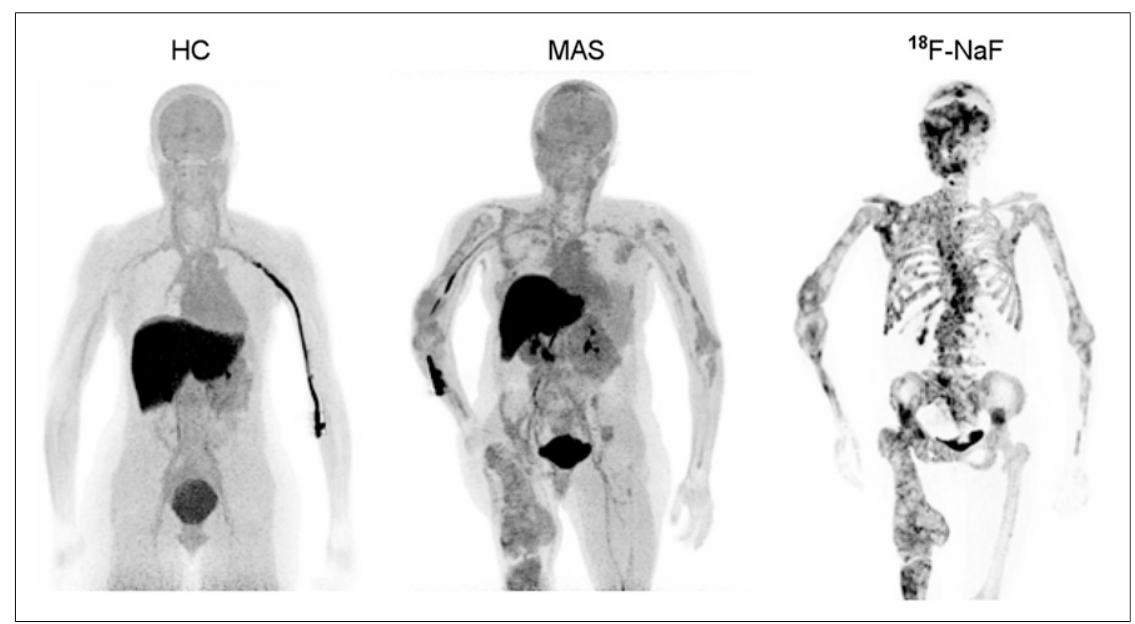

FIGURE 1. ${ }^{11} \mathrm{C}-(R)$-rolipram binding was colocalized with dysplastic bone in individuals with MAS. Maximum-intensity projections of ${ }^{11} \mathrm{C}$ - $(R)$-rolipram SUV (averaged $10-30 \mathrm{~min}, 5$ frames) are shown in representative healthy control $(\mathrm{HC})$ and MAS participant 1 , as well as ${ }^{18} \mathrm{~F}-\mathrm{NaF}$ PET/CT scan of MAS participant 1 within $1 \mathrm{y}$ of ${ }^{11} \mathrm{C}$ - $(R)$-rolipram scan. Maximum-intensity projection image projects voxels with maximum intensity in visualization plane onto 2-dimensional image.

\section{Statistical Analysis}

Differences in age, sex, injected activity, molar activity, and mass dose were calculated using Student $t$ tests. Differences in ${ }^{11} \mathrm{C}-(R)-$ rolipram uptake in organs were calculated using 1-way ANOVA.

\section{RESULTS}

Whole-body scans with ${ }^{11} \mathrm{C}-(R)$-rolipram were performed on 6 healthy controls and 6 individuals with MAS. One of the healthy control scans was stopped early at approximately $60 \mathrm{~min}$ after injection because the participant had a panic attack. Brain scans with ${ }^{11} \mathrm{C}-(R)$-rolipram and full arterial sampling were performed on 8 healthy controls and 3 individuals with MAS. For one of the healthy control scans, however, an arterial line failure occurred $15 \mathrm{~min}$ after injection, and the data were thus not used for this study. Sex, injected activity, molar activity, and mass dose did not differ between groups (Table 1). Although the age of the MAS participants ( $39 \pm 2 \mathrm{y}$ ) was greater $(P=0.025)$ than that of the controls ( $28 \pm 3 \mathrm{y})$, no studies have reported that age affects ${ }^{11} \mathrm{C}-(R)$-rolipram binding.

\section{Identification of Dysplastic Bone by ${ }^{11} \mathrm{C}$-(R)-Rolipram}

${ }^{11} \mathrm{C}-(R)$-rolipram uptake was higher in bones affected by fibrous dysplasia than in either the unaffected bones of individuals with MAS or the same bones in healthy controls (Figs. 1 and 2). In all 4 MAS participants who had a previously acquired ${ }^{18} \mathrm{~F}-\mathrm{NaF}$ bone scan for clinical purposes, ${ }^{11} \mathrm{C}-(R)$-rolipram uptake colocalized with increased remodeling seen on the bone scan for most but not all regions (Fig. 1). The ${ }^{18} \mathrm{~F}-\mathrm{NaF}$ bone scans were acquired $11 \pm 13$ mo (range, 0-29 mo) before the PET rolipram scan in the 4 MAS participants who had a bone scan.

To assess uptake in peripheral organs, we measured the area under the curve of the concentration of radioactivity versus time from 30 to $120 \mathrm{~min}$ versus the concentration of radioactivity (SUV-min). The latter portions of the time-activity curve were used because earlier intervals (e.g., 0-30 min) are strongly affected by blood flow to the organ. The area under the curve for 8 organs did not differ significantly between MAS participants and healthy controls (Supplemental Table 1). Because endocrine abnormalities are common in MAS, the thyroid and adrenal gland were visually examined and, similarly to healthy controls, both appeared normal in size on the CT image, with little ${ }^{11} \mathrm{C}-(R)$ rolipram uptake.

\section{No Evidence of Mosaicism in Brains of MAS Participants}

Brain uptake of ${ }^{11} \mathrm{C}-(R)$-rolipram was visually similar in MAS participants and healthy controls; that is, the uptake was fairly uniform, and no brain region was clearly elevated in MAS participants, regardless of whether they had neuropsychiatric symptoms. To highlight potential regional differences, uptake was normalized in each participant to the global average in that participant; again, no regional differences were apparent on visual inspection. To determine whether a global change might have occurred in MAS participants and healthy controls, uptake (as $V_{\mathrm{T}}$ ) was also analyzed, and no global or regional differences were observed (Fig. 3). $V_{\mathrm{T}}$ 


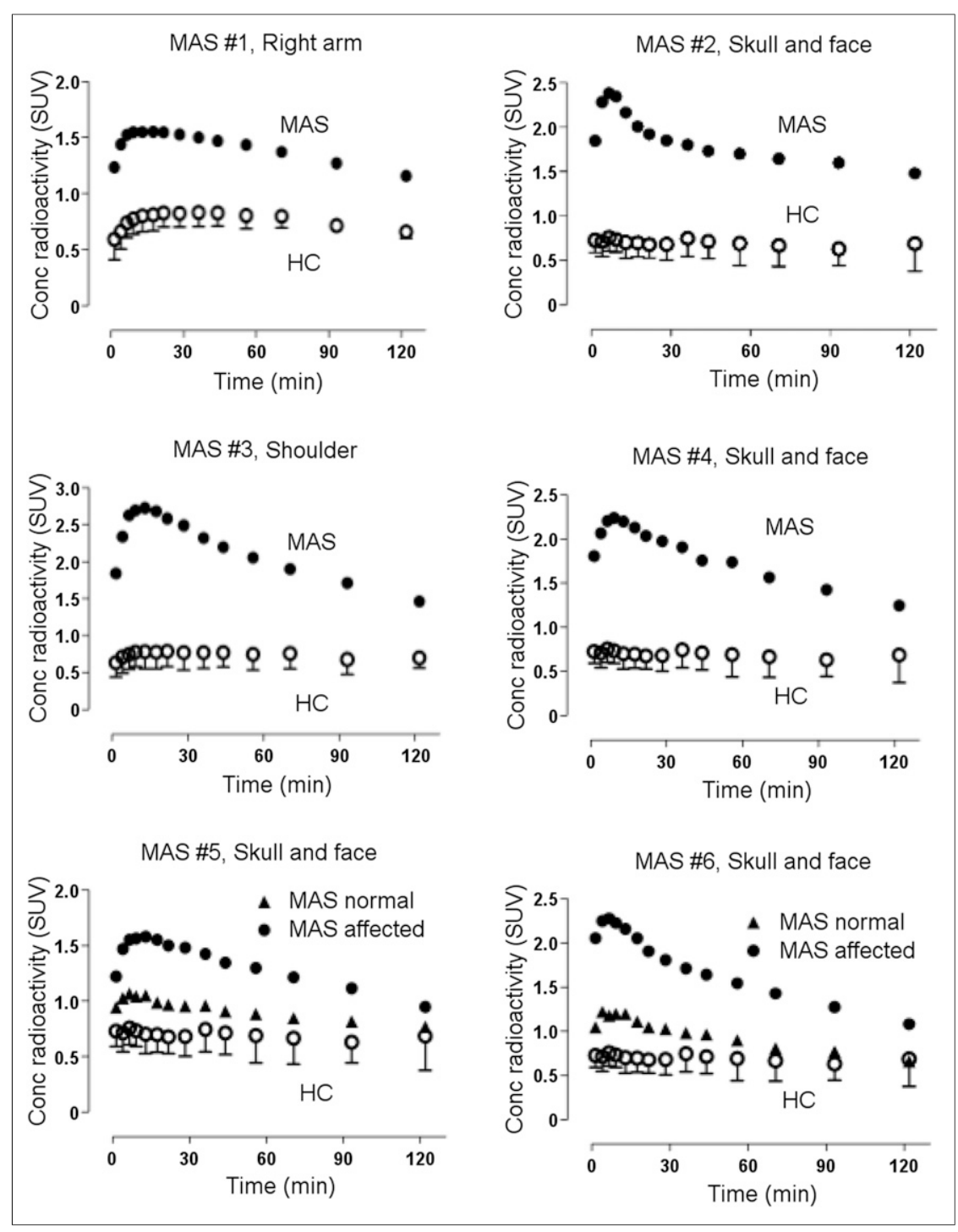

FIGURE 2. ${ }^{11} \mathrm{C}-(R)$-rolipram uptake was higher in areas of fibrous dysplasia (MAS patients) than in healthy controls. Specific regions were drawn for each MAS participant depending on location of dysplastic bone. In some MAS participants, dysplastic lesions were localized on one side, and dysplastic lesions were compared with normal lesions in same participants. Error bars show SDs.

bone but not in other peripheral organs, as shown by whole-body scans. Second, ${ }^{11} \mathrm{C}$ $(R)$-rolipram binding was not increased in the brains of individuals with MAS compared with healthy controls, and mosaicism (i.e., small areas of increased binding) was not apparent on visible inspection of the images.

In most radioligand binding studies using PET, increased uptake is caused by an increased density of the receptor or enzyme. For PDE4, however, binding of ${ }^{11} \mathrm{C}-(R)$-rolipram may also reflect a higher affinity of the enzyme for the radioligand. This is due to PKA-mediated phosphorylation of PDE4, which results not only in increased affinity for radioligand binding but also in greater enzymatic activity $(21,22)$. Consistent with this action of PKA, a previous study from our laboratory found that local injections of PKA modulators in rat brain had the expected effect on ${ }^{11} \mathrm{C}-(R)$ rolipram binding, namely that activators increased radioligand binding and inhibitors decreased binding $(16,17)$.

cAMP modulates its own activity through a negative feedback loop via 2 routes. The first route occurs quickly: increased cAMP activates PKA, which phosphorylates and activates PDE4, which then metabolizes cAMP (5). The second route occurs more slowly: prolonged PKA activation leads to phosphorylation of cAMP response elementbinding protein, which then increases the translation of PDE4 messenger RNA (2326). In this context, ${ }^{11} \mathrm{C}-(R)$-rolipram binding can be increased both by PKA-mediated phosphorylation of PDE4 and by increased synthesis of the enzyme. Both likely occur in dysplastic bone, as increased cAMP levels have been found in affected cells isolated in vitro from individuals with MAS (27-29). In fact, both routes probably occurred in our previous study, which measured ${ }^{11} \mathrm{C}-(R)$-rolipram binding in individuals with major de-

was chosen as the outcome measure instead of $V_{\mathrm{T}} / f_{\mathrm{P}}\left(V_{\mathrm{T}}\right.$ corrected for $f_{\mathrm{P}}$ ) because the sample size of this study was too small to determine whether $f_{\mathrm{P}}$ was stable within groups; thus, it was not included in order to reduce noise in the data. In addition, uptake for each region did not differ between the left and right hemispheres. For the MAS participants who had extensive craniofacial involvement and compressed brain deformation, partial-volume correction had no impact on $V_{\mathrm{T}}$ (Supplemental Fig. 2). As a result, partial-volume correction was not included in the analysis so as to not increase noise in the data.

\section{DISCUSSION}

This study, which sought to assess whether ${ }^{11} \mathrm{C}-(R)$-rolipram binding was increased in dysplastic bone and in peripheral organs of individuals with MAS versus healthy controls, had 2 major findings. First, ${ }^{11} \mathrm{C}-(R)$-rolipram binding was increased in dysplastic pressive disorder. In that study, PDE4 activity was decreased compared with controls but increased after 2 mo of treatment with a selective serotonin reuptake inhibitor (30). Thus, it is reasonable to conclude that ${ }^{11} \mathrm{C}-(R)$-rolipram binding reflects cAMP activity; nevertheless, that study could not determine whether the observed increases in ${ }^{11} \mathrm{C}-(R)$-rolipram binding were due to increased phosphorylation of PDE4, to increased gene transcription, or to both.

In the present study, the areas of skeletal uptake seen on the PDE4 whole-body images coincided with areas of uptake seen in images from previously collected ${ }^{18} \mathrm{~F}-\mathrm{NaF}$ PET/CT scans. Increased cAMP signaling leads to dysplastic bone by the abnormal function formation of osteoblasts and osteoclasts-that is, cells responsible for bone remodeling. ${ }^{18} \mathrm{~F}-\mathrm{NaF}$, which binds to the crystal surface of exposed bone, can be used to measure bone remodeling; higher binding indicates active remodeling, which underlies bone disorders such as fibrous dysplasia (31). In this study, the ${ }^{18} \mathrm{~F}-\mathrm{NaF}$ and ${ }^{11} \mathrm{C}-(R)$-rolipram images of the same 


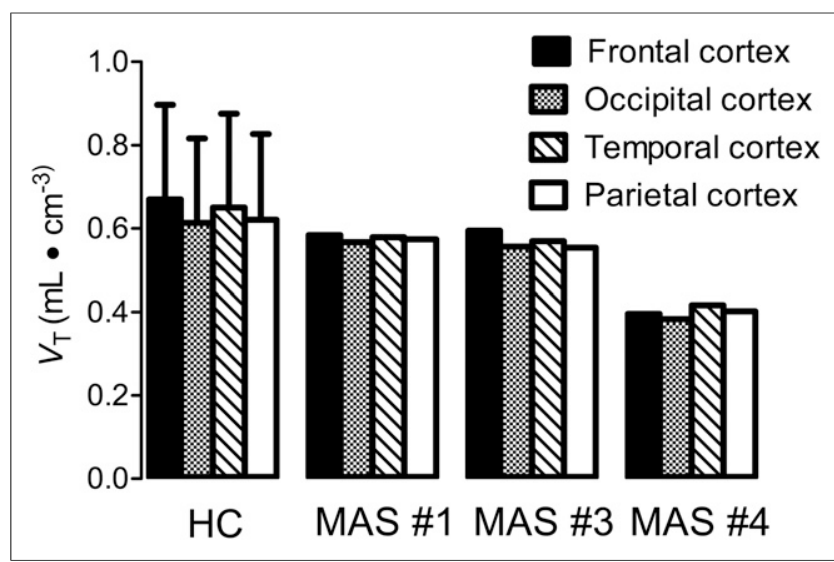

FIGURE 3. No evidence of mosaicism was observed in different brain regions of participants with MAS. ${ }^{11} \mathrm{C}$ - $(R)$-rolipram uptake in brain, measured as $V_{\mathrm{T}}$, was unchanged across brain regions in both healthy controls $(\mathrm{HC})$ and individuals with MAS. Error bars show SDs.

MAS participants showed a high degree of concordance, indicating that increased cAMP activity was colocalized with areas of active fibrous dysplasia bone remodeling (Fig. 1).

To be clear, we do not have definitive evidence that increased uptake of ${ }^{11} \mathrm{C}-(R)$-rolipram in dysplastic bone reflects binding to PDE4. Nevertheless, increased specific binding is the most likely explanation for 2 reasons. First, if the effect was merely due to increased blood flow, the organ would have both a faster uptake and a faster washout. Instead, dysplastic bone had a delayed peak and a slow washout (Fig. 2), consistent with high-affinity binding to a target that slows washout from the organ. Second, in vitro analyses of affected tissue have shown an elevated concentration of cAMP and of PDEs. Thus, the mutation has 2 effects: it increases the density of the target protein, and it increases the affinity for the radioligand via PKA-mediated phosphorylation. Arguably, the best evidence for specific binding would be a displacement study with a clinically approved PDE4 inhibitor such as roflumilast. We explored this possibility during this study, but we felt it would be unsafe. On the basis of the doses and plasma concentration in animals, the necessary human dose would 10- to 100fold higher than that associated with severe nausea and vomiting.

PET radioligands can provide excellent pharmacologic selectivity for the intended target; for example, ${ }^{11} \mathrm{C}-(R)$-rolipram reflects binding to PDE4 but not to other PDEs (specifically, PDE1 through PDE11) (32). However, the anatomic resolution of PET is limited to about 2-4 mm. Thus, small changes can be overlooked if the signal is below the limit of detection or if it is diluted by a surrounding and larger unaffected region. In fact, this errorcalled the partial-volume effect-likely occurred in the current study. In endocrine organs, increased cAMP activity has been found to lead to disorders such as hyperthyroidism in MAS (33), but no such changes were detected with PET imaging in the current study. In fact, the same may be true of brain. The prevalence of neuropsychiatric disorders in MAS led us to hypothesize that cAMP mosaicism in the brain would mimic that in the periphery. However, one possible reason for these results, outside the limitations of this study, is that the $G_{s} \alpha$ mutation did not affect the central nervous system of these MAS participants. Negative results could also be due to a type II error, meaning that although differences in brain uptake could be detected, it is likely that our methods were not sensitive enough. Possible explanations for the lack of sensitivity are that the study had too few MAS participants, that only 2 participants had any neuropsychiatric symptoms, and that abnormalities in smaller brain regions could not be detected by the low resolution of the PET scan.

\section{CONCLUSION}

Whole-body and brain PET scans were performed with the PDE4 radiotracer ${ }^{11} \mathrm{C}-(R)$-rolipram on individuals with MAS and healthy controls. Increased ${ }^{11} \mathrm{C}-(R)$-rolipram binding was found in dysplastic bone but not in other peripheral organs. No visual evidence of mosaicism was observed in brain, but small regions may not be detectable by the relatively low resolution of PET. This study is the first to confirm that ${ }^{11} \mathrm{C}-(R)$-rolipram, a radiolabeled inhibitor of PDE4, can measure the known increases in cAMP activity in vivo found in MAS. In addition, this study supports the utility of such PET scans to indirectly measure altered cAMP signaling in other human diseases, including major depressive disorder, if the abnormality extends to adequately sized regions of the target organ.

\section{DISCLOSURE}

This study was funded by the Intramural Research Programs of the National Institute of Mental Health (ZIAMH002852 and ZIAMH002793) and the National Institute of Dental and Craniofacial Research (ZIADE000649), National Institutes of Health. No other potential conflict of interest relevant to this article was reported.

\section{ACKNOWLEDGMENTS}

We are grateful to the staff of the Molecular Imaging Branch for subject recruitment, to the NIH's PET Department (chief, Peter Herscovitch, MD) for performing the PET scans, and to Ioline Henter for invaluable editorial assistance.

\section{KEY POINTS}

QUESTION: Can ${ }^{11} \mathrm{C}-(R)$-rolipram binding detect the expected increased cyclic adenosine monophosphate (cAMP) signaling in dysplastic bone of individuals with MAS, a rare genetic mosaic disorder associated with excessive production of cAMP?

PERTINENT FINDINGS: ${ }^{11} \mathrm{C}-(R)$-rolipram identified areas of dysplastic bone in individuals with MAS but did not visualize increased uptake in any other organ, some of which presumably had small areas of increased CAMP signaling.

IMPLICATIONS FOR PATIENT CARE: These findings have no direct implications for clinical care; instead, they provide pathophysiologic knowledge from living participants of the presence of increased CAMP signaling in affected areas of bone.

\section{REFERENCES}

1. Weinstein LS, Shenker A, Gejman PV, Merino MJ, Friedman E, Spiegel AM. Activating mutations of the stimulatory $\mathrm{G}$ protein in the McCune-Albright syndrome. N Engl J Med. 1991;325:1688-1695.

2. Boyce AM, Florenzano P, de Castro LF, Collins MT. Fibrous dysplasia/McCuneAlbright syndrome. In: Adam MP, Ardinger HH, Pagon RA, et al.., eds. GeneReviews. Seattle, WA: University of Washington; 1993. 
3. Mehats C, Andersen CB, Filopanti M, Jin S-LC, Conti M. Cyclic nucleotide phosphodiesterases and their role in endocrine cell signaling. Trends Endocrinol Metab. 2002;13:29-35.

4. Nemoz G, Sette C, Hess M, Muca C, Vallar L, Conti M. Activation of cyclic nucleotide phosphodiesterases in FRTL-5 thyroid cells expressing a constitutively active Gs $\alpha$. Mol Endocrinol. 1995;9:1279-1287.

5. Houslay MD, Adams DR. PDE4 cAMP phosphodiesterases: modular enzymes that orchestrate signalling cross-talk, desensitization and compartmentalization. Biochem J. 2003;370:1-18.

6. Houslay MD, Sullivan M, Bolger GB. The multienzyme PDE4 cyclic adenosine monophosphate-specific phosphodiesterase family: intracellular targeting, regulation, and selective inhibition by compounds exerting anti-inflammatory and antidepressant actions. Adv Pharmacol. 1998;44:225-342.

7. Richter W, Menniti FS, Zhang HT, Conti M. PDE4 as a target for cognition enhancement. Expert Opin Ther Targets. 2013;17:1011-1027.

8. Hsiao EC, Boudignon BM, Chang WC, et al. Osteoblast expression of an engineered Gs-coupled receptor dramatically increases bone mass. Proc Natl Acad Sci USA. 2008;105:1209-1214.

9. Palmisano B, Spica E, Remoli C, et al. RANKL inhibition in fibrous dysplasia of bone: a preclinical study in a mouse model of the human disease. $J$ Bone Miner Res. 2019;34:2171-2182

10. Weinstein LSG. $\mathrm{G}_{\mathrm{s}} \alpha$ mutations in fibrous dysplasia and McCune-Albright syndrome. J Bone Miner Res. 2006;21(suppl 2):120-124.

11. Brown RJ, Kelly MH, Collins MT. Cushing syndrome in the McCune-Albright syndrome. J Clin Endocrinol Metab. 2010;95:1508-1515.

12. Bourtchouladze R, Patterson SL, Kelly MP, Kreibich A, Kandel ER, Abel T. Chronically increased $\mathrm{G}_{\mathrm{s}} \alpha$ signaling disrupts associative and spatial learning. Learn Mem. 2006;13:745-752.

13. Kelly MP, Cheung YF, Favilla C, et al. Constitutive activation of the G-protein subunit $\mathrm{G} \alpha$ s within forebrain neurons causes PKA-dependent alterations in fear conditioning and cortical Arc mRNA expression. Learn Mem. 2008;15: 75-83.

14. Kelly MP, Isiegas C, Cheung YF, et al. Constitutive activation of G $\alpha$ s within forebrain neurons causes deficits in sensorimotor gating because of PKA-dependent decreases in cAMP. Neuropsychopharmacology. 2007;32:577-588.

15. Kelly MP, Stein JM, Vecsey CG, et al. Developmental etiology for neuroanatomical and cognitive deficits in mice overexpressing Galphas, a G-protein subunit genetically linked to schizophrenia. Mol Psychiatry. 2009;14:398415,347 .

16. Itoh T, Abe K, Hong J, et al. Effects of cAMP-dependent protein kinase activator and inhibitor on in vivo rolipram binding to phosphodiesterase 4 in conscious rats. Synapse. 2010;64:172-176.

17. Itoh T, Abe K, Zoghbi SS, et al. PET measurement of the in vivo affinity of ${ }^{11} \mathrm{C}$ (R)-rolipram and the density of its target, phosphodiesterase-4, in the brains of conscious and anesthetized rats. J Nucl Med. 2009;50:749-756.

18. Fujita M, Zoghbi SS, Crescenzo MS, et al. Quantification of brain phosphodiesterase 4 in rat with (R)-[ $\left[{ }^{11} \mathrm{C}\right]$ rolipram-PET. Neuroimage. 2005;26:12011210 .
19. Fujita M, Hines CS, Zoghbi SS, et al. Downregulation of brain phosphodiesterase type IV measured with ${ }^{11} \mathrm{C}$-(R)-rolipram positron emission tomography in major depressive disorder. Biol Psychiatry. 2012;72:548-554.

20. Lohith TG, Zoghbi SS, Morse CL, et al. Brain and whole-body imaging of nociceptin/orphanin FQ peptide receptor in humans using the PET ligand ${ }^{11} \mathrm{C}$ NOP-1A. J Nucl Med. 2012;53:385-392.

21. Hoffmann R, Wilkinson IR, McCallum JF, Engels P, Houslay MD. cAMPspecific phosphodiesterase HSPDE4D3 mutants which mimic activation and changes in rolipram inhibition triggered by protein kinase A phosphorylation of Ser-54: generation of a molecular model. Biochem J. 1998;333:139-149.

22. Zanotti-Fregonara P, Zoghbi SS, Liow JS, et al. Kinetic analysis in human brain of $\left[{ }^{11} \mathrm{C}\right](\mathrm{R})$-rolipram, a positron emission tomographic radioligand to image phosphodiesterase 4: a retest study and use of an image-derived input function. Neuroimage. 2011;54:1903-1909.

23. Conti M, Beavo J. Biochemistry and physiology of cyclic nucleotide phosphodiesterases: essential components in cyclic nucleotide signaling. Annu Rev Biochem. 2007;76:481-511.

24. Conti M, Jin S-LC, Monaco L, Repaske DR, Swinnen JV. Hormonal regulation of cyclic nucleotide phosphodiesterases. Endocr Rev. 1991;12:218-233.

25. Conti M, Richter W, Mehats C, Livera G, Park JY, Jin C. Cyclic AMP-specific PDE4 phosphodiesterases as critical components of cyclic AMP signaling. J Biol Chem. 2003;278:5493-5496.

26. Sette C, Conti M. Phosphorylation and activation of a cAMP-specific phosphodiesterase by the cAMP-dependent protein kinase. J Biol Chem. 1996;271: 16526-16534.

27. Marie PJ, de Pollak C, Chanson P, Lomri A. Increased proliferation of osteoblastic cells expressing the activating $\mathrm{G}_{\mathrm{s}} \alpha$ mutation in monostotic and polyostotic fibrous dysplasia. Am J Pathol. 1997;150:1059-1069.

28. Sette C, Vicini E, Conti M. Modulation of cellular responses by hormones: role of CAMP specific, rolipram-sensitive phosphodiesterases. Mol Cell Endocrinol. 1994;100:75-79.

29. Yamamoto T, Ozono K, Kasayama S, et al. Increased IL-6 production by cells isolated from the fibrous bone dysplasia tissues in patients with McCuneAlbright syndrome. J Clin Invest. 1996;98:30-35.

30. Fujita M, Richards EM, Niciu MJ, et al. cAMP signaling in brain is decreased in unmedicated depressed patients and increased by treatment with a selective serotonin reuptake inhibitor. Mol Psychiatry. 2017;22:754-759.

31. Papadakis GZ, Manikis G, Karantanas A, et al. ${ }^{18} \mathrm{~F}-\mathrm{NaF}$ PET/CT imaging in fibrous dysplasia of bone. J Bone Miner Res. 2019;34:1619-1631.

32. Schneider HH, Schmiechen R, Brezinski M, Seidler J. Stereospecific binding of the antidepressant rolipram to brain protein structures. Eur J Pharmacol. 1986; 127:105-115.

33. Robinson C, Collins MT, Boyce AM. Fibrous dysplasia/McCune-Albright syndrome: clinical and translational perspectives. Curr Osteoporos Rep. 2016;14: $178-186$.

34. Collins MT, Kushner H, Reynolds JC, et al. An instrument to measure skeletal burden and predict functional outcome in fibrous dysplasia of bone. $J$ Bone Miner Res. 2005;20:219-226. 